\title{
PERAMALAN STOK OBAT DI PUSKESMAS GENDING PROBOLINGGO MENGUNAKAN METODE WINTER'S EXPONENTIAL SMOOTHING
}

\author{
Luqman Affandi ${ }^{1}$, Hendra Pradibta ${ }^{2}$, Muhammad Ishaq Habibi ${ }^{3}$ \\ ${ }^{1,2}$ Jurusan Teknologi Informasi, Program Studi Teknik Informatika, ${ }^{3}$ Politeknik Negeri Malang \\ laffandi@yahoo.com ${ }^{1}$, hendra.pradibta@polinema.ac.id ${ }^{2}$, st ishaq habibi@yahoo.com ${ }^{3}$
}

\begin{abstract}
Abstrak
Pembelian stok obat di Puskesmas Gending Probolinggo masih memiliki beberapa kendala misalnya terjadi penumpukan atau kekurangan stok obat. Hal tersebut dikarenakan puskesmas tersebut masih melakukan pembelian stok obat secara konstan setiap periodenya. Hal ini tentunya mengakibatkan terjadinya penumpukan stok obat apabila terjadi penurunan penjualan obat. Sebaliknya, apotik akan kekurangan stok apabila terjadi lonjakan penjualan obat.

Oleh karena itu, dibuatlah sistem peramalan stok obat berbasis web dengan menerapkan metode Winters Exponential Smoothing untuk mempermudah puskesmas tersebut dalam melakukan pembelian stok obat. Metode ini diterapkan untuk melakukan peramalan jumlah stok obat yang akan dibeli pada periode berikutnya.Parameter yang digunakan dalam metode ini menggunakan data penjualan obat bulanan tahun 2015 2016. Selanjutnya data tersebut diuji menggunakan metode ini sehingga menghasilan tingkat akurasi peramalan Mean Absolute Percentage Error (MAPE) yang tinggi, yaitu di atas 20\%.
\end{abstract}

Kata kunci: peramalan, winters exponential smoothing, puskesmas gending probolinggo. penjualan obat.

\section{Pendahuluan}

Pertumbuhan Teknologi Informasi di Puskesmas Gending Probolinggo adalah sarana layanan kesehatan masyarakat milik pemerintah kabupaten Probolinggo. Salah satu layanan kesehatan yang diberikan adalah layanan penyediaan obat. Instalasi Farmasi merupakan bagian dari Puskemas Gending Probolinggo yang khusus ditugaskan mengelola obat untuk kebutuhan pasien rumah sakit.

Dalam pengendalian persediaan, bagian gudang Puskesmas Gending Probolinggo dilakukan secara manual, dimana jumlah obat yang dipesan setiap bulan sama dengan jumlah obat yang dipesan pada bulan-bulan sebelumnya. Sehingga hal ini menimbulkan berbagai macam permasalahan. Permintaan kebutuhan jumlah obat yang tidak pasti dalam tiap periodenya membuat petugas kesulitan dalam memperkirakan kebutuhan obat untuk masa yang akan datang. Ketidaktepatan dalam menentukan waktu dan jumlah obat yang akan dipesan mengakibatkan kehabisan stok dan keterlambatan dipenuhinya pesanan obat oleh supplier, sehingga tidak dapat memenuhi permintaan pasien pada saat memesan.

Peramalan bukanlah hal yang baru di dunia industri. Sudah banyak penelitian-penelitian terdahulu dilakukan karena peramalan memang dipandang dapat memaksimalkan biaya penyetokan barang. Titania Dwi Andini dan Probo Auristandi
(2016) dalam penelitiannya membuat peramalan jumlah stok alat tulis kantor di UD Achmad Jaya menggunakan metode double exponential smoothing, permasalahannya UD Achmad Jaya mengalami kesulitan saat memprediksikan stok yang harus diambil dalam bulan berikutnya. Adapun metode yang dapat memberi solusi dari peramalan tersebut yaitu metode double exponential smoothing. Metode ini dapat digunakan karena pola data penjualan alat tulis kantor berunsur trend. Penelitian selanjutnya dilakukan oleh Eka Mala Sari, Yeni K, dan Rizki S (2015) dengan judul Sistem Peramalan Stok Obat Menggunakan Metode Exponential Smoothing. Permasalan yang muncul Instalasi Farmasi RSUD Syarifah Ambami Rato Ebu bangkalan hanya sebatas rekap penjualan obat tanpa ada pengolahan data sehingga pihak farmasi kesulitan dalam meramalkan stok obat yang akan muncul pada periode mendatang. Pada metode exponential smoothing dibutuhkan suatu konstanta pemulusan yang baik untuk mengurangi mean percentage error dari hasil peramalan. Dari sistem peramalan ini akan didapatkan laporan estimasi biaya stok obat shingga pihak Puskesmas mampu mempersiapkan anggaran pengeluaran dengan tepat.

Berdasarkan uraian permasalahan yang ada di bagian gudang Instalasi Farmasi Puskesmas Gending Probolinggo, maka untuk mengatasi permasalahan tersebut, diperlukan adanya suatu 
sistem informasi pengendalian persediaan obat. Dalam sistem informasi ini, untuk menentukan permintaan kebutuhan jumlah obat yang tidak pasti di masa mendatang dengan menggunakan suatu metode peramalan. Metode peramalan yang akan digunakan disesuaikan dengan pola data rekap penjualan obat perbulan pada tahun 2015 (2 tahun).Berdasarkan studi lieteratur yang digunakan untuk meramalkan stok yang akan datang adalah winter's exponential smoothing. Metode ini dapat digunakan karena pola data stok obat mempunyai 2 karakteristik unsur trend dan musiman (peningkatan pada bulan tertentu) sehingga grafik data yang dihasilkan mengalami kenaikan atau penurunan yang sangat cepat. Sedangkan untuk membantu proses putaran persediaan, sistem menyediakan informasi stok obat saat ini dan informasi obat yang dapat diresepkan kepada pasien. Dengan sistem informasi pengendalian persediaan obat ini bagian gudang Instalasi Farmasi Puskesmas Gending Probolinggo diharapkan dapat mengendalikan persediaan obat agar persediaan obat tetap terjaga, tepat waktu, dan dapat selalu mencukupi permintaan pasien..

\subsection{Rumusan Masalah}

Berdasarkan latar belakang tersebut, rumusan masalahnya adalah bagaimana bagian instalasi farmasi pada Puskesmas Gending Probolinggo dapat meramalkan stok obat yang akan datang agar tidak terjadi penumpukan ataupun kekurangan stok obat?

\subsection{Batasan Masalah}

1. Membuat sistem peramalan stok obat di Puskesmas Gending Probolinggo

2. Bahasa pemrograman yang digunakan adalah PHP dan database Mysql.

3. Metode yang digunakan adalah winter's exponential smoothing

4. Variabel yang digunakan data stok obat tahun 2015 dan 2016 dengan parameter penjualan per bulan.

\subsection{Tujuan}

Membangun sistem peramalan stok obat di Puskesmas Gending Probolinggo menggunakan metode Winter's Exponential Smoothing untuk menghidari terjadinya penumpukan ataupun kekurangan stok obat.

\section{Landasan Teori}

\subsection{Puskesmas Gending Probolinggo}

Puskesmas Gending Probolinggo adalah suatu perusahaan layanan kesehatan masyarakat yang berlokasi di Kota Gending Kab. Probolinggo. Dikarenakan pada puskesmas ini belum mempunyai sistem yang digunakan untuk rekomendasi pembelian obat untuk periode selanjutnya maka perlu dibuatkan sistem peramalan stok obat untuk periode selanjutnya.

\subsection{Winters Exponential Smoothing}

Exponential smoothing adalah metode pemulusan yang bobotnya berciri menurun secara eksponensial dari titik data terakhir sampai dengan yang terawal. Metode ini terdiri atas tunggal, ganda, Holt's Model, Winter's Model, yang semuanya mempunyai sifat yang sama yaitu nilai yang lebih baru diberikan bobot yang relatif besar dibanding nilai observasi yang lebih lama. Persamaan yang digunakan untuk metode Exponential Smoothing model Winter's menggunakan 4 persamaan antara lain :

Pemulusan Eksponensial :

$\mathrm{S} \_\mathrm{t}=\alpha \mathrm{X}$-t/I_(t-L) $+(1-\alpha)\left(\mathrm{S} \_(\mathrm{t}-1)+\mathrm{b} \_(\mathrm{t}-1)\right)(1)$

Estimasi Tren :

$$
\text { b_t }=\beta\left(S \_t-S \_(t-1)\right)+(1-\beta) b \_(t-1)(2)
$$

Estimasi Musiman :

$$
\text { I_t }=\text { V X_t } / S \_t+(1-\gamma) I \_(t-L)
$$

Nilai Peramalan :

Dimana :

$$
F \_(t+m)=\left(S \_t-b \_t ~ m\right) I \_(t-L+m)(4)
$$

$F_{-}(\mathrm{t}+\mathrm{m})=$ nilai ramalan

$\alpha=$ konstanta pemulusan $(0<\alpha<1)$

$\mathrm{X} \_\mathrm{t}=$ Data sebenarnya pada waktu ke- $\mathrm{t}$

$\beta^{-}=$konstanta pemulusan untuk perkiraan trend $(0<\beta<1)$

b_t $=$ perkiraan tren

$\mathrm{Y}=$ konstanta pemulusan untuk perkiraan musiman $(0<\mathrm{\gamma}<1)$

I_t $=$ perkiraan musiman

$\mathrm{m} \quad=$ periode mendatang yang akan diramalkan

$\mathrm{L} \quad=$ lebar musiman

Dari persamaan rumus diatas bisa di ambil kesimpulan bahwa konstanta alfa, beta dan gamma merupakan masukan yang sangat mempengaruhi ketepatan peramalan dari metode ini. Keuntungan dari Exponential Smoothing Model Winter's ini adalah peneliti bisa meramalkan beberapa periode kedepan dengan nilai ketepatan yang lebih akurat (Andini, 2016).

\section{Metodologi Penelitian}

\subsection{Desain Penelitian}

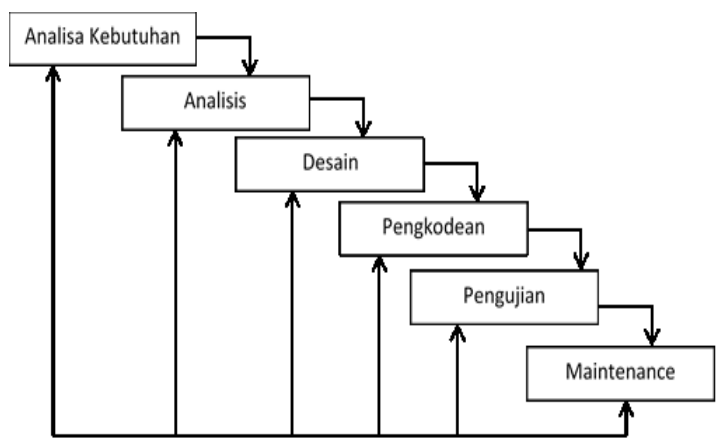

Gambar 1. Waterfall Sistem 
Penelitian ini dilakukan dengan beberapa tahap yaitu:

1. Tahapan Analisa Kebutuhan

Pada tahap ini melakukan observasi ke Puskesmas Gending Probolinggo guna mencari data-data yang dibutuhkan. Dari hasil observasi tersebut didapat sebuah data laporan stok obat pada Puskesmas Gending Probolinggo, dari laporan tersebut didapat beberapa data antara lain: stok awal, penerimaan, persediaan, pemakaian, sisa stok, rata-rata/bulan, permintaan yang dibutuhkan dalam pembuatan sistem.

\section{Tahapan Analisis}

Pada tahap ini melakukan analisis terhadap data-data yang diperoleh dari hasil observasi sesuai dengan permasalahan yang ada. Dari data-data hasil observasi tersebut di analisis kemudian disimpulkan parameter yang digunakan dalam peramalan stok obat antara lain data pemakaian, permintaan, dan rata-rata/bulan sehingga didapatkan hasil peramalan yang akurat.

\section{Tahapan Desain}

Pada tahap ini desain dikerjakan setelah selesai menganalisis data-data hasil observasi yang telah dikumpulkan secara lengkap, maka dilakukan pembuatan desain sistem dengan menggunakan metode winter's exponential smoothing.

4. Tahapan Pengkodean

Pada tahap ini, desain program diterjemahkan ke dalam kode-kode dengan menggunakan bahasa pemrograman yang sudah ditentukan. Pada tahap ini, dibuat program atau dapat dikatakan mengimplementasikan tahap desain yang kemudian diterjemahkan ke dalam kode-kode program (script program) dengan menggunakan bahasa pemrograman yang sudah ditentukan yaitu HTML, PHP, dan MySQL sebagai database-nya. Adapun aplikasi lain yang digunakan seperti Adobe Dreamweaver dan XAMPP. Pada tahap ini pengodean dilakukan secara berkala, maksutnya akan dilakukan tahap demi tahap agar program dapat terselaesaikan dengan baik.

\section{Tahapan Pengujian}

Pada tahap ini akan dilakukan pengujian pada program. Pengujian yang digunakan yaitu pengujian black-box Testing, yaitu menguji perangkat lunak dari segi spesifikasi fungsional tanpa menguji desain dan kode program. Pengujian black-box dilakukan dengan membuat kasus uji yang bersifat mencoba semua fungsi dengan memakai perangkat lunak apakah sesuai dengan spesifikasi yang dibutuhkan. Seperti halnya menguji pada bagian login, menginputkan username dengan benar dan password yang salah atau menginputkan username dan password yang salah, jika berhasil login maka dapat dikatakan program masih belum berjalan dengan baik. Beberapa pengujian dilakukan dengan program yang sesuai dengan desain/kebutuhan.

\section{Tahapan Maintenance}

Pemeliharaan suatu software diperlukan, termasuk di dalamnya adalah pengembangan, karena software yang dibuat tidak selamanya hanya seperti itu. Ketika dijalankan mungkin saja masih ada kesalahan kecil yang tidak ditemukan sebelumnya, atau ada penambahan fitur-fitur yang belum ada pada perangkat lunak tersebut.

\section{Perancangan}

Perancangan desain sistem dapat menggunakan model, model yang digunakan untuk menggambarkan alur proses aplikasi perancangan sistem peramalan stok obat di Puskesmas Gending Probolinggo dengan menggunakan metode winter's exponential smoothing sebagai berikut :

\section{Use case}

Use Case diagram adalah diagram yang menyajikan interaksi antara use case dan actor. Dimana actor dapat berupa orang, peralatan atau sistem lain yang berinteraksi dengan sistem yang sedang dibangun. Use case menggambarkan

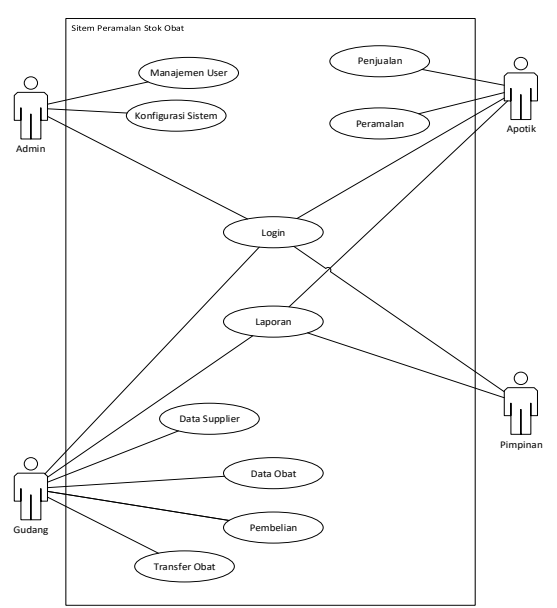

fungsionalitas sistem atau persyaratan-persyaratan yang harus dipenuhi sistem dari pandangan 
pemakai. Alur sistem Proses Sistem digambarkan pada gambar 3 .

Gambar 2 Use Case Sistem

2. Class Diagram

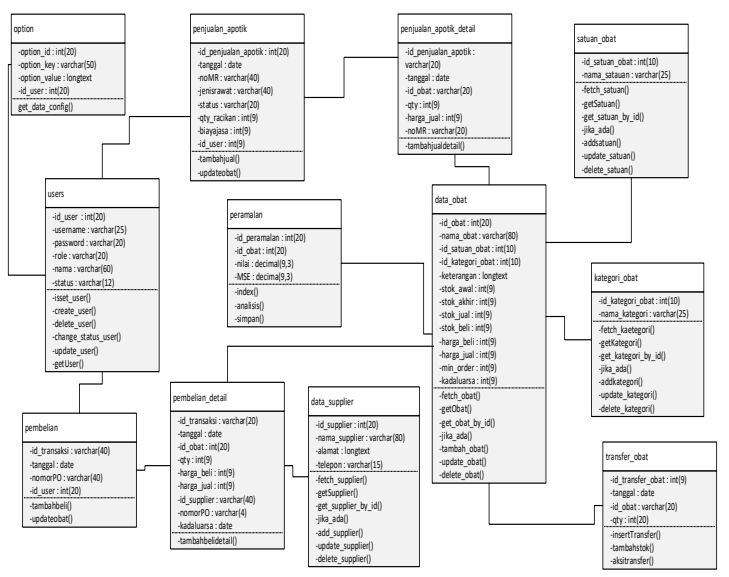

Class Diagram adalah suatu diagram yang digunakan untuk menggambarkan beberapa class dan fungsi dari tiap-tiap class yang digunakan dalam sistem. Diagram class juga dapat diartikan sebagai kumpulan obyek-obyek yang mempunyai struktur dan relasi antar obyek tersebut. Class Diagram yang digunakan dalam sistem ini ditunjukkan pada gambar 3 .

Gambar 3. Class Diagram

\section{Entity Relationship Diagram}

Entity Relationship Diagram

(ERD) ditunjukkan pada gambar 4.

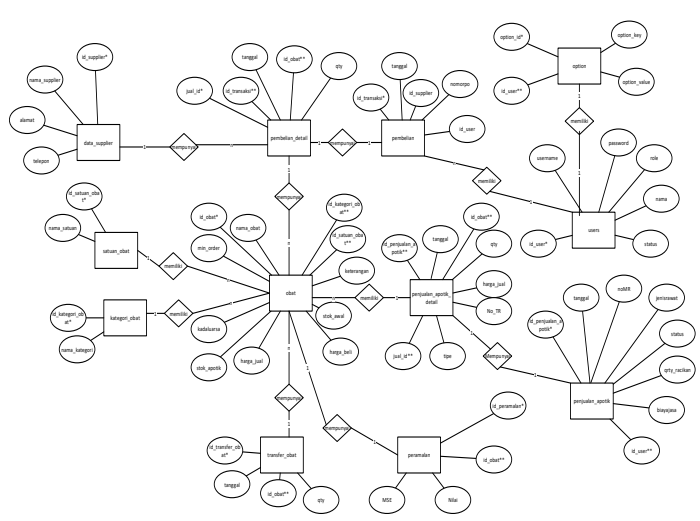

Gambar 4. Entity Relationship Diagram

\section{Hasil dan Pembahasan}

Sampel data penjualan obat di Puskesmas Gending Probolinggo akan diuji keakuratan hasil peramalannya lalu dihitung berapa MAPE (Mean Absolute Error). Sebelum melakukan peramalan sistem akan mencari nilai $\alpha=(0<\alpha<1), \beta=(0<\beta$ $<1)$ dan $\mathrm{\gamma}=(0<\mathrm{\gamma}<1)$. Nilai $\alpha$ merupakan nilai konstanta exponential, nilai $\beta$ merupakan nilai konstanta trend, nilai $\mathrm{V}$ merupakan nilai konstanta musiman.

Selanjutnya sistem akan melakukan pengulangan 3 kali dengan nilai penjualan data obat yang akan diramalkan, kemudian sistem akan memilih nilai MAPE yang paling kecil. Setelah mendapatkan nilai $\alpha, \beta$, dan $\mathrm{Y}$ sistem akan menampilkan hasil peramalan. Setelah itu hasil peramalan akan diuji keakuratannya menggunakan rumus MAPE. Data yang digunakan 24 periode terakhir mulai tahun 2015-2016 dengan data obat Klorfeniramin maleat (CTM) tab $4 \mathrm{mg}$ dan Amoksisilin $500 \mathrm{mg}$ pada tabel 6.1 dan 6.12 hasil peramalan pada gambar 6 .

Tabel 1, Data Obat Klorfeniramin maleat (CTM) tab $4 \mathrm{mg}$

\begin{tabular}{|c|c|c|c|}
\hline No & $\begin{array}{l}\text { Data } \\
\text { Asli }\end{array}$ & $\begin{array}{c}\text { Hasil } \\
\text { Peramalan } \\
\end{array}$ & $\begin{array}{l}\text { Persentase } \\
\text { Error (PE) }\end{array}$ \\
\hline 1 & 2806 & 2284 & $19 \%$ \\
\hline 2 & 2893 & 2227 & $24 \%$ \\
\hline 3 & 4083 & 2934 & $29 \%$ \\
\hline 4 & 3248 & 4217 & $29 \%$ \\
\hline 5 & 3221 & 4040 & $25 \%$ \\
\hline 6 & 2309 & 3343 & $44 \%$ \\
\hline 7 & 1773 & 2279 & $28 \%$ \\
\hline 8 & 2690 & 1340 & $51 \%$ \\
\hline 9 & 2541 & 2072 & $19 \%$ \\
\hline 10 & 2820 & 2647 & $7 \%$ \\
\hline 11 & 1955 & 2932 & $49 \%$ \\
\hline 12 & 735 & 2210 & $100 \%$ \\
\hline
\end{tabular}

Dengan nilai $\alpha=0.5, \beta=0.9$, dan $\mathrm{Y}=0.6$

$$
P E=\frac{X t-F t}{X t} \times 100 \%=\frac{2806-2284}{5539} \times 100 \%=19 \%
$$

$$
\begin{array}{ll}
\mathrm{PE} & =\text { Nilai error ramalan } \\
\mathrm{Xt} & =\text { Nilai data asli } \\
\mathrm{Ft} & =\text { Nilai ramalan }
\end{array}
$$




$$
\begin{aligned}
& M A P E=\sum_{t=1}^{n} \frac{P E}{n}=\frac{423}{12}=35,3 \% \\
& \text { MAPE }=\text { Rata-rata keseluruhan error } \\
& \mathrm{n} \quad=\text { Jumlah data }
\end{aligned}
$$

\begin{tabular}{|c|c|c|c|}
\hline No & $\begin{array}{l}\text { Data } \\
\text { Asli } \\
\end{array}$ & $\begin{array}{c}\text { Hasil } \\
\text { Peramalan } \\
\end{array}$ & $\begin{array}{l}\text { Persentase } \\
\text { Error (PE) }\end{array}$ \\
\hline 1 & 4022 & 3394 & $16 \%$ \\
\hline 2 & 3435 & 4147 & $20 \%$ \\
\hline 3 & 5100 & 3777 & $26 \%$ \\
\hline 4 & 4508 & 5241 & $14 \%$ \\
\hline 5 & 3553 & 4899 & $37 \%$ \\
\hline 6 & 2580 & 3969 & $53 \%$ \\
\hline 7 & 3085 & 2887 & $7 \%$ \\
\hline 8 & 3178 & 3095 & $3 \%$ \\
\hline 9 & 3379 & 3223 & $5 \%$ \\
\hline 10 & 3875 & 3422 & $12 \%$ \\
\hline 11 & 3186 & 3895 & $22 \%$ \\
\hline 12 & 3871 & 3381 & $13 \%$ \\
\hline
\end{tabular}

Tabel 2, Data Obat Amoksilin 500 mg

Dengan nilai $\alpha=0.8, \beta=0.1$, dan $\gamma=0.1$

$$
\begin{aligned}
& P E=\frac{x t-F t}{x t} \times 100 \%=\frac{4022-3394}{4022} \times 100 \%=16 \% \\
& M A P E=\sum_{t=1}^{n} \frac{P E}{n}=\frac{228}{12}=19 \%
\end{aligned}
$$

Rata-rata error dari kedua data $=\frac{35.3+19}{2}=27.15 \%$

Berikut adalah contoh grafik hasil dari peramalan obat. Pada grafi tersebut menunjutkkan nilai penjualan, nilai eksponensial smoothing, dan nilai peramalan

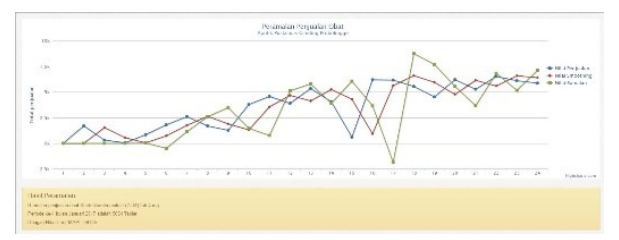

Gambar 5. Hasil Peramalan

\subsection{Hasil Perhitungan Tingkat Efisiensi}

Dari hasil pengujian menggunakan data penjualan obat Klorfeniramin maleat (CTM) tab 4 mg dengan data 24 periode terakhir dengan nilai $\alpha$ $=0.5, \beta=0.9$, dan $\mathrm{\gamma}=0.6$ mendapat MAPE $35.3 \%$ dan menggunakan data penjualan obat Amoksisilin $500 \mathrm{mg}$ dengan nilai $\alpha=0.8, \beta=0.1$, dan $\mathrm{X}=0.1$ mendapat nilai MAPE $19 \%$, dan ratarata peramalan dari kedua obat tersebut $27.15 \%$. Sehingga peramalan ini dikatakan tidak baik, karena peramalan yang baik memiliki nilai rata-rata error dibawah 20\% [8]. Dengan demikian sistem peramalan stok obat pada Puskesmas Gending Probolinggo menggunakan Metode Winters Exponential Smoothing tidak sesuai dengan yang diharapkan.

Hasil dari pengujian fungsional sistem sudah sesuai, jadi namun akurasi untuk metode peramalan ini memiliki MAPE tinggi di atas 20\%. Hasil error yang tinggi ini dapat disebabkan oleh kurangnya data, karena dataset yang digunakan hanya 1 musim saja. Sehingga sistem ini dengan metode Winters Exponential Smoothing belum layak digunakan di Puskesmas Gending Probolinggo.

\section{Kesimpulan dan Saran \\ 5.1 Kesimpulan}

Berdasarkan hasil perhitungan peramalan yang didapatkan dari Sistem Peramalan Stok Obat di Puskesmas Gending Probolinggo menggunakan Metode Winters Exponential Smoothing dapat ditarik kesimpulan bahwa Sistem telah berhasil menerapkan metode Winters Exponential Smoothing dan telah dibuat sesuai dengan rancangan. Hasil uji coba sistem ini menunjukkan bahwa sistem ini telah dibuat sesuai dengan fungsuionalitas yang diharapkan dan tujuan untuk meramalkan stok obat di periode berikutnya sudah terpenuhi. Pengujian nilai error (akurasi peramalan) menunjukkan hasil yang tidak bagus, karena nilai error rata-rata (MAPE) menunjukkan di atas $20 \%$.

\subsection{Saran}

Dalam laporan ini di ajukan saran untuk pengembangan Sistem Peramalan stok obat di Puskesmas Gending Probolinggo yaitu menggunakan metode lain yang digunakan untuk peramalan. Dan juga disarankan untuk menggunakan dataset lebih dari 1 musim untuk menghindari error peramalan yang tinggi. 


\section{Daftar Pustaka}

Andini, dan Auristandi, Probo, "Peramalan Jumlah Stok Alat Tulis Kanntor Di UD Achmad Jaya Menggunakan Metode Double Exponential Smoothing", JITIKA vol. 10, Februari 2016.

Eka Mala Sari, Yeni Kustinyahningsih, dan Sugiharto Rizki, "Sistem Peramalan Stok Obat Menggunakan Metode Exponential Smoothing", Konferensi Nasional Sistem \& Informatika, STIKOM Bali, 9-10 Oktober 2015.

Jogiyanto, Hartono, "Pengenalan Komputer", Yogyakarta: C.V.ANDI OFFSET, 2004.

Martin Fowler, "Panduang Singkat Bahasa Pemodelan Objek Standar", Andi, Yogyakarta, 2005.Sutanta, "Basis Data dalam Tinjauan Konseptual”, Andi, 2011

Puspitosari, Heni A, " Pemrograman Web Database dengan PHP dan MySQL Tingkat Lanjut", Skripta, Malang, Juli 2010.

Titania Dwi Andini, dan Auristandi Probo,"Peramalan Jumlah Stok Alat Tulis Kantor di UD Achmad Jaya Menggunakan Metode Double Exponential Smoothing", JITIKA,vol.10, No.1, Februari 2016.

Zainun, dan Majid, "Low Cost House Demand Predictor", Universitas Teknologi Malaysia. 